\title{
Penerapan Metode K-Nearest Neighbor Untuk Klasifikasi Kinerja Satpam Berbasis Web
}

\author{
M. Raihan Alghifari, Adityo Permana Wibowo \\ ${ }^{1,2}$ Program Studi Informatika, Fakultas Teknologi Informasi dan Elektro \\ Universitas Teknologi Yogykarta \\ e-mail::[1] raihanmuhammad184@gmail.com, ${ }^{[2]}$ adityopw@staff.uty.ac.id
}

\begin{abstract}
ABSTRAK - Penilaian kinerja adalah salah satu aspek penting untuk mengembangkan sebuah organisasi atau instansi agar menjadi lebih efektif dan efisien. Dimana penilaian kinerja ini dapat dijadikan sebagai tolak ukur dalam mengambil keputusan. Sedangkan dengan tidak adanya penilaian kinerja, maka kualitas kinerja para satpam menjadi tidak terkontrol. Satpam dengan kinerja yang baik tidak akan mendapatkan penghargaan atas kinerjanya. Begitu pula sebaliknya, satpam dengan kinerja yang buruk juga tidak mendapatkan sanksi apapun. Keadaan ini akan berdampak pada menurunnya motivasi satpam untuk meningkatkan kualitas kinerja mereka dan cenderung menurun. Dengan menurunnya kinerja satpam maka akan berdampak pada menurunnya tingkat keamanan di sebuah instansi. Peneliti akan membangun sistem untuk mengklasifikasikan kinerja satpam agar menjadi referensi bagi instansi untuk bisa menindak lanjuti satpam yang memiliki kinerja yang buruk serta memberikan apresiasi bagi satpam yang kinerjanya baik. Klasifikasi tersebut dikerjakan menggunakan metode K-Nearest Neighbor untuk menghitung tingkat akurasi dari penilaian kinerja satpam. Penelitian ini akan terdapat data sebanyak 130 data dengan 10 atribut, yang berisikan tentang penilaian kinerja seperti kepribadian, kemampuan dan keterampilan. Hasil penelitian akan menghasilkan output berupa penilaian tingkat kinerja dari satpam termasuk kategori baik, cukup atau kurang. Proses penerapan metode K-Nearest Neighbor untuk klasifikasi kinerja satpam menggunakan perhitungan $\mathrm{K}=3$ sampai $\mathrm{K}=9$. Pengujian klasifikasi menggunakan 6 data uji dan menghasilkan prosentase terbesar dengan k=3 yaitu akurasi sebesar 66,67\%. Dengan demikian aplikasi ini bisa digunakan untuk membantu mengetahui kinerja satpam.
\end{abstract}

Kata Kunci : Klasifikasi, Kinerja Satpam, K-Nearest Neighbor

ABSTRACT-Performance appraisal is one of the important aspects for developing organizations or institutions to be more effective and efficient. Where the results of this assessment can be made as a benchmark in making decisions. While in the absence of Performance Resolution, the quality of the security guards' performance is out of control. Security guards with good performance will not get an award for their performance. Conversely, security guards with poor performance also do not get any sanctions. This situation will increase in decreasing security guards' motivation to improve their quality and increase. With the decreasing performance of security guards it will have an impact on the decline in the level of security in an institution. The researcher will develop a system to classify the performance of security guards so that it becomes a reference for the institution to follow up security guards who have good performance and provide appreciation for security guards whose performance is good. The classification is done by using the K-Nearest Neighbor method to calculate the level of acceptance from the security performance appraisal. This research will involve data of 130 data with 10 attributes, which contain performance such as abilities, abilities and skills. The results of the study will produce an output consisting of the results of the security guard's assessment including the categories of good, enough or less. The process of applying the K-Nearest Neighbor method for security guard performance classification uses the calculation of $K=3$ to $K=9$. The classification test uses 6 test data and produces the largest percentage with $k=3$, which is an accuracy of $66.67 \%$. Thus this application can be used to help determine the performance of security guards.

Index Terms: Classification, Security Performance, K-Nearest Neighbor

Jurnal Teknologi \& Manajemen Informatika - Vol.5 No.1 2019 


\section{PENDAhUluan}

Pendahuluan Aspek keamanan merupakan bagian terpenting untuk sebuah instansi. Satuan pengamanan (satpam) merupakan bagian dari keamanan yang dibentuk oleh sebuah instansi yang bertugas menyelenggarakan keamanan dan ketertiban di lingkungan/tempat kerjanya yang meliputi aspek pengamanan fisik, personil, informasi dan pengamanan teknis lainnya (Peraturan Kepala Kepolisian Negara Republik Indonesia Nomor 24 Tahun 2007 Tentang Sistem Manajemen Pengamanan Organisasi, Perusahaan dan/atau Instansi/Lembaga Pemerintah, BAB I, Pasal 1, Ayat 6).

Untuk menunjang baiknya aspek keamanan pada sebuah instansi, maka diperlukan adanya evaluasi penilaian kinerja satpam. Penilaian kinerja adalah salah satu aspek penting untuk mengembangkan sebuah organisasi atau instansi agar menjadi lebih efektif dan efisien[1]. Dimana penilaian kinerja ini dapat dijadikan sebagai tolak ukur dalam mengambil keputusan.

Sedangkan dengan tidak adanya penilaian kinerja, maka kualitas kinerja para satpam menjadi tidak terkontrol. Satpam dengan kinerja yang baik tidak akan mendapatkan penghargaan atas kinerjanya. Begitu pula sebaliknya, satpam dengan kinerja yang buruk juga tidak mendapatkan sanksi apapun. Keadaan ini akan berdampak pada menurunnya motivasi satpam untuk meningkatkan kualitas kinerja mereka dan cenderung menurun. Dengan menurunnya kinerja satpam maka akan berdampak pada menurunnya tingkat keamanan di suatu instansi.

Berdasarkan latar belakang di atas, peneliti akan membangun sistem untuk mengklasifikasikan kinerja satpam agar menjadi referensi bagi instansi untuk bisa menindak lanjuti satpam yang memiliki kinerja yang buruk serta memberikan apresiasi bagi satpam yang kinerjanya baik. Klasifikasi tersebut dikerjakan menggunakan metode K-Nearest Neighbor untuk menghitung tingkat akurasi dari.

\section{K-Nearest Neighbor}

Algoritma KNN adalah salah satu algoritma klasifikasi yang paling terkenal digunakan untuk memprediksi kelas dari
Alhgifari, M.Raihan (2019) catatan atau (sampel) dengan kelas yang tidak ditentukan berdasarkan kelas dari catatan tetangganya. algoritma ini terbuat dari tiga langkah sebagai berikut [2] :

a. Menghitung jarak record masukan dari semua catatan pelatihan.

b. Mengatur catatan pelatihan berdasarkan jarak dan pemilihan K-tetangga terdekat.

c. Menggunakan kelas yang memiliki mayoritas diantara k-tetangga terdekat (metode ini menganggap kelas sebagai kelas record input yang diamati lebih dari semua kelas-kelas lain antar K-tetangga terdekat).

Classifier berasumsi jarak catatan dari satu sama lain sebagai kriteria untuk kedekatan mereka dan memilih catatan paling mirip. Ada banyak metode untuk menghitung jarak seperti fungsi jarak Euclidean, Manhattan, dll, di antaranya fungsi jarak Euclidean adalah salah satu yang paling umum didefinisikan seperti pada Persamaan 1.

$\mathrm{d}\left(x_{i}, x_{j}\right)=\sqrt{\sum_{r=1}^{n}\left(a_{r}\left(x_{i}\right)-a_{r}\left(x_{j}\right)\right)^{2}}$

Ket:

$\begin{array}{ll}\mathrm{d}\left(x_{i}, x_{j}\right) & : \text { Jarak Euclidean (Eucledean } \\ & \text { Distance) } \\ \left(x_{i}\right) & \text { :record } \mathrm{ke}-i \\ \left(x_{j}\right) & : \text { record } \mathrm{ke}-\mathrm{j} \\ \left(a_{r}\right) & : \text { data ke-r } \\ i j & : 1,2,3, . . \mathrm{n}\end{array}$

Metode k-NN adalah metode yang menentukan nilai jarak pada pengujian data testing dengan data training berdasarkan nilai terkecil dari nilai ketetanggaan terdekat, didefinisikan seperti pada Persamaan 2.

$D_{n n}\left(C_{1}, C_{2}\right)=\min _{1 \leq i \leq r, 1 \leq j \leq s} d\left(y_{i}, z_{j}\right)$

\section{PHP}

PHP adalah salah satu bahasa pemrograman skrip yang dirancang untuk membangun aplikasi web. Ketika dipanggil dari web browser, program yang ditulis dengan PHP akan di-parsing di dalam web server oleh interpreter PHP dan diterjemahkan ke dalam dokumen HTML, yang selanjutnya akan ditampilkan kembali ke web browser. Karena pemrosesan program PHP dilakukan di lingkungan web 
server maka PHP dikatan sebagai bahasa sisi server. Oleh sebab itu, kode PHP tidak akan terlihat pada saat user memilih perintah "View Source" pada web browser yang mereka gunakan [3].

PHP berasal dari kata Hypertext Preprocessor, yaitu bahasa pemrograman universal untuk penanganan pembuatan dan pengembangan sebuat situs web dan bisa digunakan bersamaan dengan HTML. Saat ini, PHP banyak dipakai untuk membuat program situs web dinamis. PHP sebagai sekumpulan skrip atau bahasa pemrograman memiliki fungsi utama yaitu mampu mengumpulkan dan mengevaluasi hasil survei atau bentuk apapun ke server database dan pada tahap selanjutnya akan menciptakan efek beruntun. Efek beruntun PHP ini berupa tindakan dari skrip lain yang akan melakukan komunikasi dengan database, mengumpulkan dan mengelompokkan informasi, kemudian menampilkanya pada saat ada tamu website memerlukanya [4].

\section{Basis Data}

Basis data adalah suatu pengorganisasian sekumpulan data yang saling terkait sehingga memudahkan aktivitas untuk memperoleh informasi. Basis data dimaksudkan untuk mengatasi problem pada sistem yang memakai pendekatan berbasis berkas [5].

\section{Entity Relationship Diagram (ERD)}

Entitiy Relationship Diagram (ERD) adalah pemodelan awal basis data yang akan dikembangkan berdasarkan teori himpunan dalam bidang matematika untuk pemodelan basis data relasional [6].

ERD memiliki beberapa aliran notasi seperti notasi Chen (dikembangkan oleh Peter Chen). Barker (dikembangkan oleh Richard Barker, Ian Palmer, Harry Ellis), notasi Crow's Foot, dan beberapa notasi lain. Namun yang banyak digunakan adalah notasi dari Chen.

\section{Data Flow Diagram (DFD)}

Pendekatan analisis terstruktur dikembangkan oleh Chris Gane dan Gane Sarson (1979) melalui buku metodologi Jurnal Teknologi \& Manajemen Informatika - Vol.5 No.1 2019 struktur analisis dan desain sistem informasi. Mereka menyarankan untuk menggunakan Data Flow Diagram (DFD) dalam menggambarkan atau membuat model sistem. Namanya, DFD seakan-akan mencerminkan penekanan pada data, namun sebenarnya DFD lebih menekankan segi proses. DFD sering juga digunakan untuk menggambarkan suatu sistem yang telah ada atau sistem yang baru yang akan dikembangkan secara logika tanpa mempertimbangkan lingkungan fisik dimana data tersebut mengalir (misal lewat telfon atau surat) serta lingkungan fisik dimana data tersebut akan disimpan (misal hard disk atau disket).

Tahapan-tahapan perancangan dengan menggunakan DFD sebagai berikut [6] :

a. Membuat DFD Level 0 atau Context Diagram

DFD Level 0 menggambarkan sistem yang akan dibuat sebagai suatu entitas tunggal yang berinteraksi dengan orang maupun sistem lain. DFD Level 0 digunakan untuk menggambarkan interaksi antara sistem yang akan dikembangkan dengan entitas luar.

b. Membuat DFD Level 1

DFD Level 1 digunakan untuk menggambarkan modul-modul yang ada dalam sistem yang akan dikembangkan. DFD Level 1 merupakan hasil breakdown DFD Level 0 yang sebelumnya dibuat.

c. Membuat DFD Level 2

Modul-modul pada DFD Level 1 dapat di-breakdown menjadi DFD Level 2. Modul mana saja yang harus dibreakdown lebih detail tergantung pada tingkat kedetailan modul tersebut. Apabila modul tersebut sudah cukup detail dan rinci maka modul tersebut sudah tidak perlu untuk di-breakdown lagi. Untuk sebuah sistem, jumlah DFD Level 2 sama dengan jumlah modul pada DFD Level 1 yang di-breakdown.

d. Membuat DFD Level 3 dan seterusnya DFD Level 3, 4, 5 dan seterusnya 
merupakan breakdown dari modul pada DFD Level diatasnya. Breakdown pada Level 3, 4, 5 dan seterusnya aturanya sama persis dengan DFD Level 1 atau Level 2.

\section{METODOLOGI PENELITIAN Pengumpulan Data}

a. Ambil Data

Pengambilan data merupakan proses mendapatkan data dari seorang ahli atau sebuah instansi. Pada penelitian ini keperluan data penelitian akan diambil data dari penelitian [7].

b. Filtering Data

Filtering data merupakan penyaringan data-data yang diperlukan. Pada penelitian ini data yang dibutuhkan berupa penilaian-penilaian untuk meninjau kinerja dari satpam yang mencangkup kepribadian, kemampuan, dan keterampilan.

\section{Desain dan Pembuatan Program}

Pada penelitian ini pembuatan program akan dilakukan dengan menggambarkan alur jalannya program dan tampilan program yang ditunjukkan oleh flowchart, desain, tools yang akan dipakai, dan metode yang akan digunakan.

a. Flowchart

Flowchart yang menggambarkan alur kerja program klasifikasi kinerja satpam dengan metode KNN terlihat pada Gambar 1.

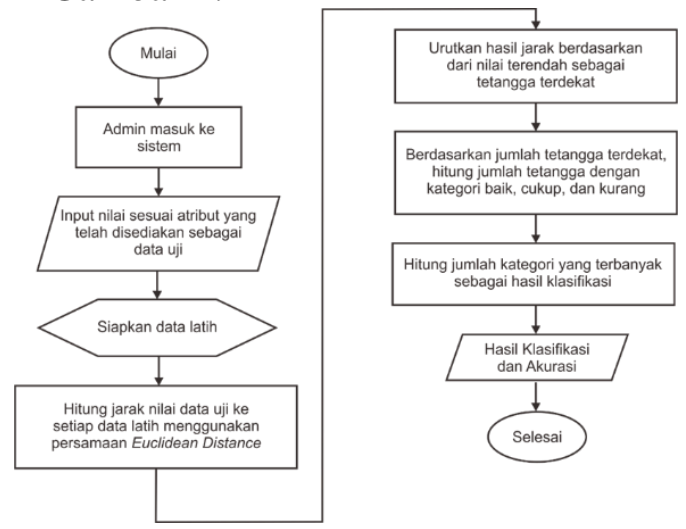

Gambar 1. Flowchart Program

b. Desain

Pada desain program akan terdapat tampilan form input untuk memberikan nilai-nilai ke 10 atribut yang telah disediakan seperti kemampuan verbal,
Alhgifari, M.Raihan (2019)

kemampuan spasial, kemampuan numerik, kebanggaan, kualitas hidup, affective commitment, continuance commitment, normative commitment, tanggung jawab, dan keterampilan.

c. Pembuatan Program

Pembuatan program ini menggunakan bahasa pemrograman PHP (PHP: Hypertext Preprocessor) untuk pengkodean HTMLnya dan juga CSS (Cascading Style Sheets) untuk mengatur penampilan suatu dokumen yang ditulis dalam bahasa markup. Selanjutnya yaitu memggunakan JavaScript untuk membuat program yang merupakan bahasa pemrograman berbasis prototipe yang berjalan disisi klien. Perancangan pada Database menggunakan ERD (Entity Relationship Diagram), untuk Database Server menggunakan MySQL.

d. Algoritma Metode K-Nearest Neighbor Pada pembuatan sistem klasifikasi kinerja satpam ini menggunakan metode K-Nearest Neighbor. Langkah-langkah dari metode K-Nearest Neighbor adalah:

1. Menentukan nilai dari 0-100 pada kolom kemampuan verbal, kemampuan spasial, kemampuan numerik, kebanggaan, kualitas hidup, affective commitment, continuance commitment, normative commitment, tanggung jawab, dan keterampilan yang akan diinputkan sebagai data uji.

2. Menentukan nilai $\mathrm{K}$ dari $\mathrm{k}=3, \mathrm{k}=5$, $\mathrm{k}=7$, dan $\mathrm{k}=9$.

3. Menghitung nilai-nilai yang sudah diinputkan sebagai data uji dengan 136 record pada data latih untuk mendapatkan jarak euclidean.

4. Mengurutkan hasil dari jarak euclidean setiap data latih dari yang terkecil, dilihat dari jumlah $\mathrm{K}$, jika jumlah $\mathrm{k}=3$ maka diambil tiga jarak terkecil, kemudian jika $\mathrm{k}=5$ maka diambil lima jarak terkecil, begitu juga seterusnya hingga $\mathrm{k}=9$.

5. Menghitung jumlah kategori baik, cukup, dan buruk yang didapat dari $\mathrm{k}$ jarak yang terkecil, lalu diambil kategori dengan jumlah yang paling 
banyak. Semisal pada $\mathrm{k}=3$ terdapat jumlah kategori baik=2, cukup=1, buruk $=0$ maka dapat ditarik kesimpulan kategori dari data uji yang diinputkan adalah baik dan begitu juga seterusnya hingga $\mathrm{k}=9$.

\section{Desain dan Pembuatan Program}

Uji coba akan dilakukan dengan metode Black Box Testing. Black Box Testing adalah pengujian yang dilakukan hanya mengamati hasil eksekusi melalui data uji dan memeriksa fungsional dari perangkat lunak.

\section{HASIL DAN PEMBAHASAN Analisa Kebutuhan}

Sistem ini akan memiliki beberapa proses, yaitu pengolahan data latih, data uji, dan data akurasi. Perangkat lunak yang dibangun membutuhkan beberapa masukan, yaitu:

a. Data latih yang sudah disediakan untuk proses perhitungan k-nn dengan data uji.

b. Data uji yang sudah memiliki kinerja awal dan akan dibandingkan dengan hasil kinerja dari proses perhitungan knn untuk memperoleh akurasi kebenaran dan akurasi kesalahan.

Dalam Sistem Klasifikasi Kinerja Satpam dengan Metode K-NN yang akan dibangun ini, admin dapat melakukan input dan edit untuk data latih dan melukakan input data uji yang sudah memiliki kinerja awal untuk menghitung akurasi serta bisa juga menginputkan data uji baru untuk mengecek hasil kinerjanya dengan proses perhitungan metode k-nn.

\section{Rancangan Sistem}

Rancangn sistem yang akan dibangun berupa perancangan entity relationship diagram (ERD), struktur tabel, relasi antar tabel, data flow diagram (DFD), diagram konteks, serta perancangan tampilan website.

1. Entity Relationship Diagram (ERD)

ERD adalah model data untuk menggambarkan hubungan antara satu entitas dengan entitas lain yang mempunyai relasi (hubungan). Pada sistem ini terdapat entitas hitung, data_uji, dan data_latih. ERD yang Jurnal Teknologi \& Manajemen Informatika - Vol.5 No.1 2019 terdapat dalam klasifikasi kinerja satpam dapat dilihat pada Gambar 2.

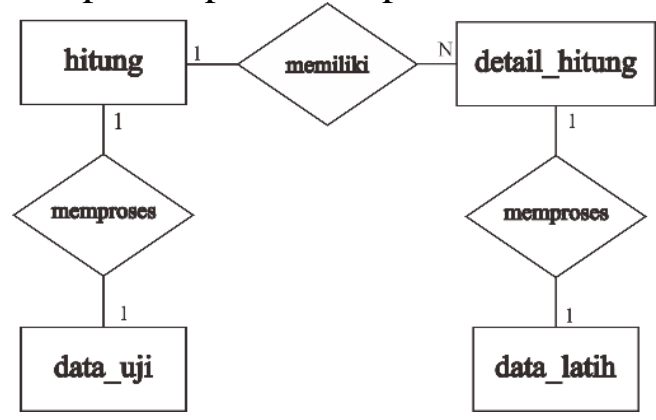

Gambar 2. ERD

\section{Struktur Tabel}

a. Tabel Data Latih

Tabel data latih berfungsi untuk menyimpan data latih yang terdiri dari 11 kolom yaitu id_data_latih, k_verbal, k_numerik, k_spasial, bangga, kualitas_hidup, ac, cc, nc, tanggung_jawab, keterampilan, dan kinerja_satpam. Tabel data latih dapat dilihat pada Tabel 1.

Tabel 1. Tabel Data Latih

\begin{tabular}{|l|l|l|l|}
\hline Kolom & Tipe & $\begin{array}{l}\text { Pjg } \\
\text { Data }\end{array}$ & Status \\
\hline id_data_latih & integer & 11 & Primary Key \\
\hline nama & varchar & 50 & \\
\hline k_verbal & integer & 11 & \\
\hline k_numerik & integer & 11 & \\
\hline k_spasial & integer & 11 & \\
\hline bangga & integer & 11 & \\
\hline kualitas_hidup & float & & \\
\hline ac & float & & \\
\hline cc & float & & \\
\hline nc & float & & \\
\hline tanggung_jawab & float & & \\
\hline keterampilan & integer & 11 & \\
\hline kinerja_satpam & enum & & (“baik”,"cukup”, \\
& & & "buruk”) \\
\hline
\end{tabular}

b. Tabel Data Uji

Tabel data uji berfungsi untuk menyimpan data uji yang terdiri dari 11 kolom yaitu id_data_latih, k_verbal, k_numerik, k_spasial, bangga, kualitas_hidup, ac, $\mathrm{cc}$, nc, tanggung_jawab, keterampilam dan kinerja_awal. Tabel data uji dapat dilihat pada Tabel 2. 
Tabel 2. Tabel Data Uji

\begin{tabular}{|l|l|c|c|}
\hline \multicolumn{1}{|c|}{ Kolom } & \multicolumn{1}{c|}{ Tipe } & $\begin{array}{c}\text { Panjang } \\
\text { Data }\end{array}$ & \multicolumn{1}{c|}{ Status } \\
\hline id_data_latih & integer & 11 & Primary Key \\
\hline nama & varchar & 50 & \\
\hline k_verbal & integer & 11 & \\
\hline k_numerik & integer & 11 & \\
\hline k_spasial & integer & 11 & \\
\hline bangga & integer & 11 & \\
\hline kualitas_hidup & float & & \\
\hline ac & float & & \\
\hline cc & float & & \\
\hline nc & float & & \\
\hline tanggung_jawab & float & & \\
\hline keterampilan & integer & 11 & \\
\hline kinerja_awal & enum & & (“baik","cukup”, \\
& & & "buruk") \\
\hline
\end{tabular}

c. Tabel Hitung

Tabel hitung berfungsi untuk mengoperasikan perhitungan metode KNN dengan memakai data dari data latih dan data uji. Tabel hitung terdiri dari 7 kolom yaitu id_hitung, id_data_uji, jumlah_k, dan kinerja_satpam, seperti dapat dilihat pada Tabel 3.

Tabel 3. Tabel Hitung

\begin{tabular}{|l|l|c|l|}
\hline \multicolumn{1}{|c|}{ Kolom } & \multicolumn{1}{c|}{ Tipe } & $\begin{array}{c}\text { Panjang } \\
\text { Data }\end{array}$ & \multicolumn{1}{c|}{ Status } \\
\hline id_hitung & integer & 11 & Primary Key \\
\hline id_data_uji & integer & 11 & Foreign Key \\
\hline jumlah_k & integer & 11 & \\
\hline kinerja_satpam & enum & & $\begin{array}{l}\text { (“baik","cukup", } \\
\text { "buruk") }\end{array}$ \\
\hline
\end{tabular}

\section{Relasi Antar Tabel}

Relasi antar tabel ini menjelaskan hubungan antar tebel yang digunakan dalam sistem. Relasi tabel dapat dilihat pada Gambar 3.
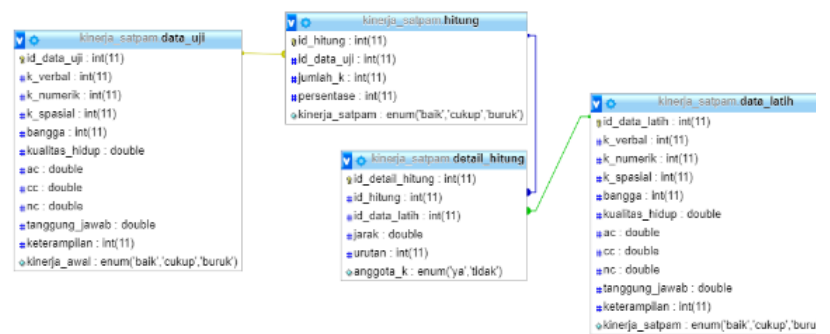

Gambar 3. Relasi Antar Tabel

\section{Data Flow Diagram}

a. Diagram Konteks

Diagram Konteks ini merupakan bagian dari level tertinggi dari DFD (Data Flow Diagram) yang menggambarkan seluruh input ke suatu sistem atau output dari
Alhgifari, M.Raihan (2019)

sistem. Diagram Konteks yang menggambarkan seluruh kerja sistem dapat dilihat pada Gambar 4.

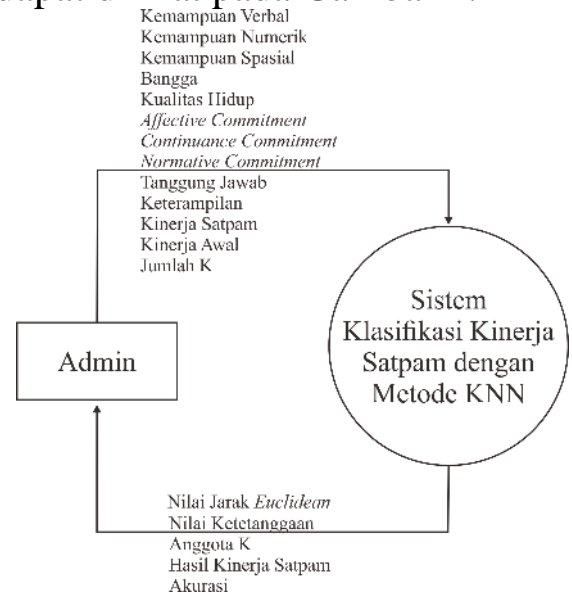

Gambar 4. Diagram Konteks

b. DFD Level 1

DFD level 1 adalah diagram yang menggambarkan level 1 pada diagram jenjang yaitu proses input data uji, input data latih, hitung, dan hasil. DFD level 1 dapat dilihat pada Gambar 5.

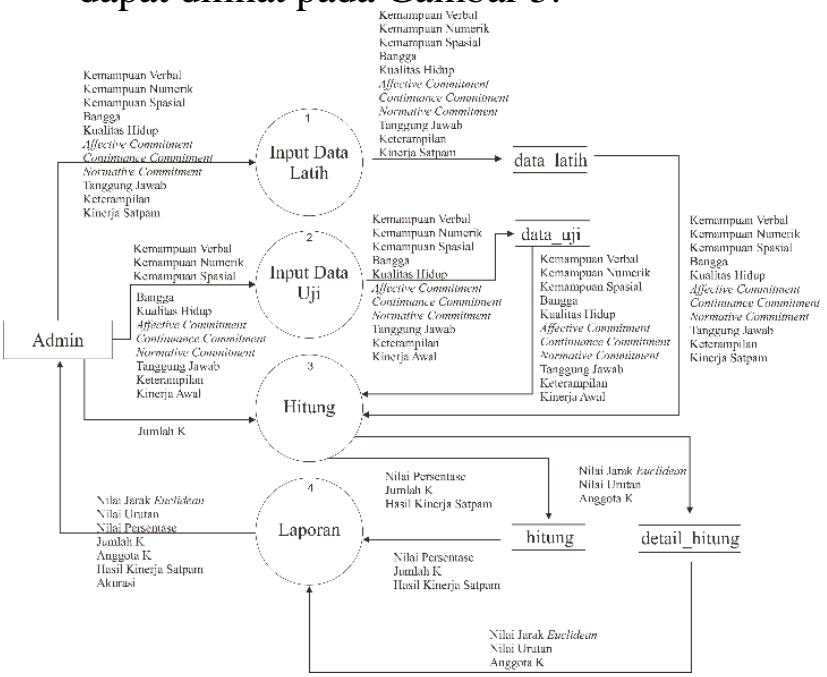

Gambar 5. DFD Level 1

\section{c. DFD Level 2 Proses 3}

DFD level 2 proses 3 adalah penjabaran dari proses hitung yang didalamnya ada proses hitung jarak euclidean, hitung ketetanggaan, hitung nili kinerja $\mathrm{k}$ yang nantinya akan disimpan pada tabel hitung. DFD level 2 proses 3 dapat dilihat pada Gambar 6. 


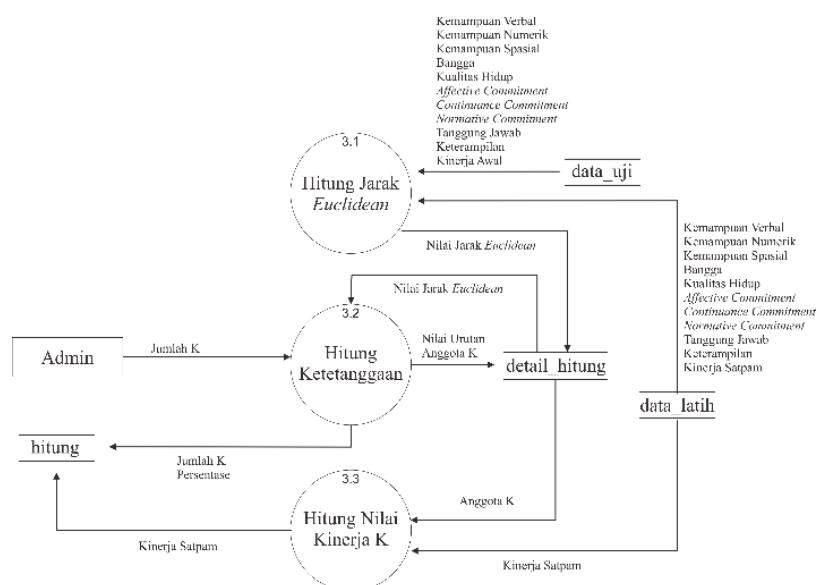

Gambar 6. DFD Level 2 Proses 3

\section{Simulasi Perhitungan KNN}

Perhitungan KNN berdasarkan data latih sebanyak 130 data yang sudah terdapat nilai kinerja. Misalkan terdapat data baru untuk menguji kinerjanya, data tersebut adalah :

1. Komunikasi Verbal $=80$

2. Komunikasi Numerik $\quad=80$

3. Komunikasi Spasial $=90$

4. Bangga $=90$

5. Kualitas Hidup $\quad=70$

6. Afective Commitmen $=70$

7. Continuance Commitment $=60$

8. Normative Commitment $=60$

9. Tanggung Jawab $=80$

10. Keterampilan $=90$

Berikut langkah-langkah untuk perhitungannya :

1. Hitung nilai data uji yang telah diinputkan dengan memakai rumus yang terlihat pada Persamaan 1. Proses perhitungan dengan membandingkan sebanyak 130 data latih seperti pada Tabel 5.

Tabel 5. Jarak Euclidean

\begin{tabular}{|c|c|}
\hline No & $\begin{array}{c}\text { Jarak } \\
\text { (Hasil dari perhitungan antara data uji } \\
\text { dengan seluruh data latih per baris) }\end{array}$ \\
\hline 1. & 42,08 \\
\hline 2. & 43,72 \\
\hline 3. & 43,63 \\
\hline 4. & 34,04 \\
\hline 5. & 43,73 \\
\hline$\ldots$ & $\ldots$ \\
\hline 130. & 97,50 \\
\hline
\end{tabular}

2. Masukkan nilai $\mathrm{K}$, sebagai percobaan nilai $\mathrm{k}=3$. Memakai $\mathrm{k}=3$ karena nilai $\mathrm{k}$ yang besar akan membuat batasan antara setiap klasifikasi menjadi lebih kabur dan juga $\mathrm{k}=3$ mendapatkan salah satu akurasi paling tinggi dari $\mathrm{k}=5, \mathrm{k}=7$, dan $\mathrm{k}=9$.

3. Dengan menggunakan $\mathrm{k}=3$, maka didapatkan hasil jarak terdekat dan hasil kinerjanya dapat dilihat pada Tabel 6.

Tabel 6. Jarak Euclidean Terdekat

\begin{tabular}{|l|c|c|c|}
\hline Data ke- & Jarak & Urutan & $\begin{array}{c}\text { Kinerja } \\
\text { Satpam }\end{array}$ \\
\hline Data ke-4 & 34,04 & 1 & "baik" \\
\hline Data ke-16 & 38,78 & 3 & "baik" \\
\hline Data ke-95 & 34,08 & 2 & "cukup" \\
\hline
\end{tabular}

4. Dapat ditarik kesimpulan kinerja dari dara uji adalah baik karena perhitungan k-nn menggunakan data yang paling mayoritas yaitu didapati 3 data yang mempunyai jarak terdekat dengan komposisi kinerja 2 baik dan 1 cukup.

\section{Tampilan Program}

a. Halaman Awal Program

Tampilan awal program berisi judul dari sistem dan terdapat button untuk memulai sistem seperti dapat dilihat pada Gambar 7.

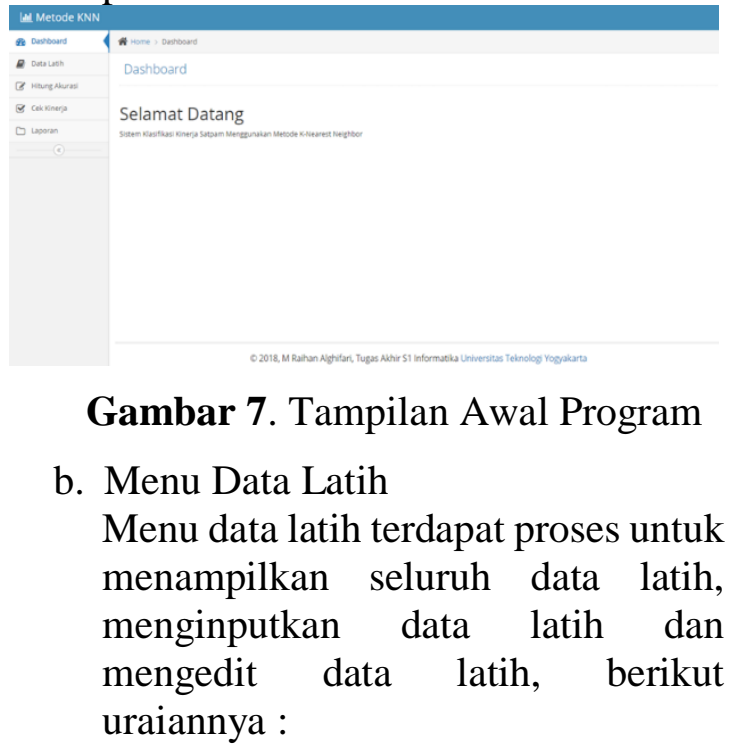


1. Tampilan Data Latih

Tampilan seluruh data latih yang sudah diinputkan ke database seperti pada Gambar 8.

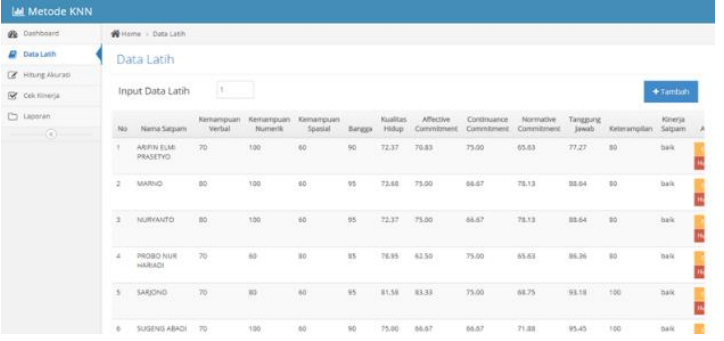

Gambar 8. Tampilan Data Latih

2. Tampilan Input Data Latih

Tampilan proses penginputan data latih dapat dilihat pada Gambar 9.

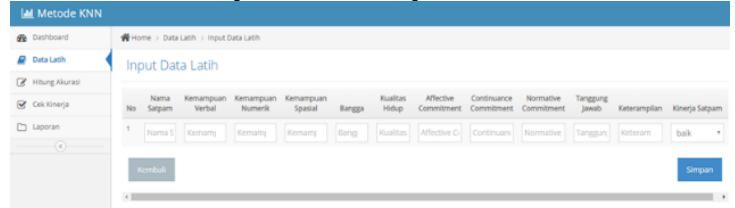

Gambar 9. Tampilan Input Data Latih

\section{Tampilan Edit Data Latih}

Tampilan proses edit data latih dapat dilihat pada Gambar 10.

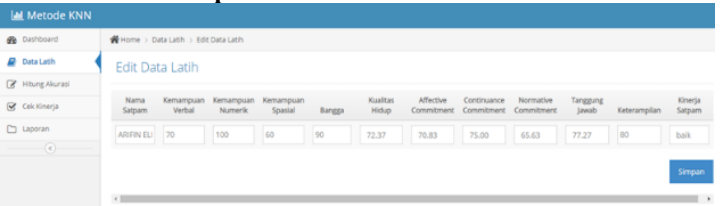

Gambar 10. Tampilan Edit Data Latih

c. Menu Hitung Akurasi

Menu hitung akurasi terdapat proses menampilkan seluruh data uji serta akurasi kebenaran dan kesalahannya, serta proses menginputkan data uji yang sudah memiliki kinerja awal, berikut uraiannya :

1. Tampilan Data Uji

Tampilan seluruh data uji serta akurasi kebenaran dan kesalahan dapat dilihat pada Gambar 11.
Alhgifari, M.Raihan (2019)

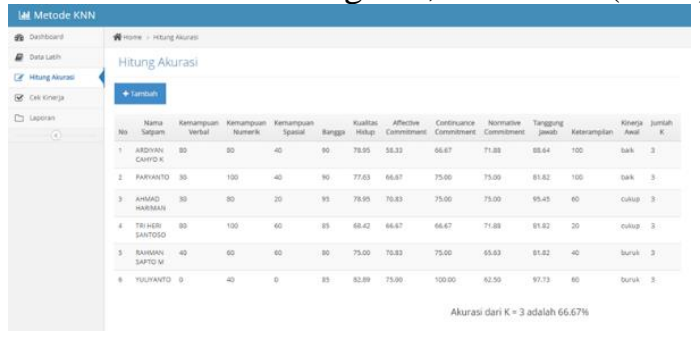

Gambar 11. Tampilan Data Uji

2. Tampilan Input Data Uji

Tampilan proses penginputan data uji yang memiliki kinerja awal dapat dilihat pada Gambar 12

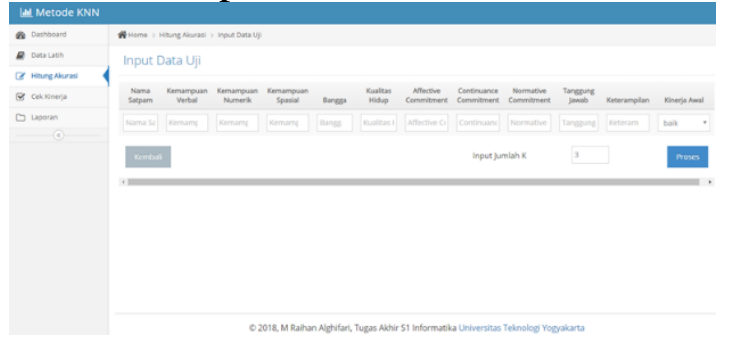

Gambar 12. Tampilan Input Data Uji

d. Menu Cek Kinerja

Menu cek kinerja terdapat proses menampilkan seluruh data uji, proses menginputkan data uji baru, dan proses menampilkan persentase dan hasil kinerja satpam dari data uji yang baru diinputkan, berikut uraiannya :

1. Tampilan Input Data Uji Baru Tampilan proses penginputan data uji baru dapat dilihat pada Gambar 13.

Gambar 13. Tampilan Input Data Uji Baru

2. Tampilan Persentase dan Hasil Kinerja Data Uji Baru

Tampilan setelah data uji baru diproses akan menghasilkan persentase dan hasil kinerja satpamnya, seperti pada Gambar 14. 


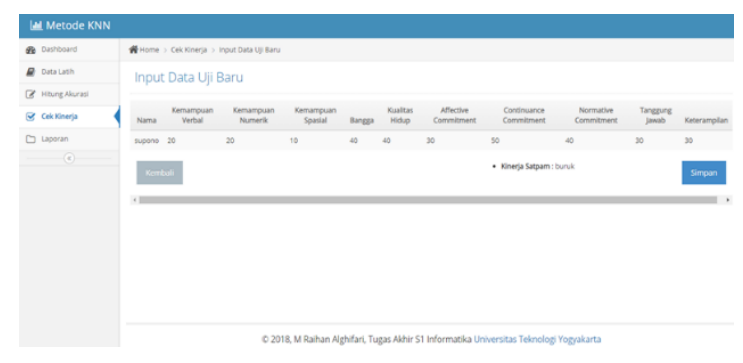

Gambar 14. Tampilan Persentase Data Uji Baru

\section{Tampilan Detail Laporan}

Tampilan detail laporan yang meliputi seluruh data latih yang dilengkapi dengan nilai jarak, urutan dan anggota $\mathrm{k}$, seperti pada Gambar 15.

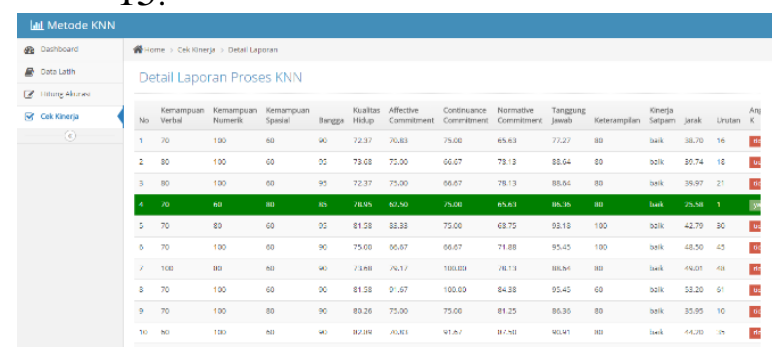

Gambar 15. Tampilan Detail Laporan

\section{Tampilan Seluruh Data Uji}

Tampilan seluruh data uji serta persentase dan hasil kinerja yang dihasilkan, dapat dilihat pada Gambar 16.

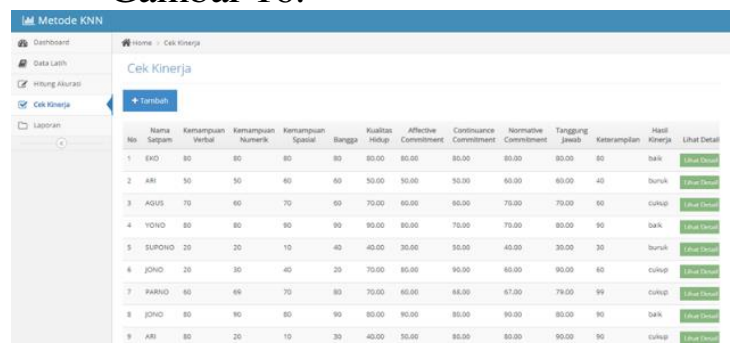

Gambar 16. Tampilan Seluruh Data Uji

e. Halaman Laporan

Tampilan laporan berisi tabel yang sesuai kinerja satpam yang seperti dapat dilihat pada Gambar 17.

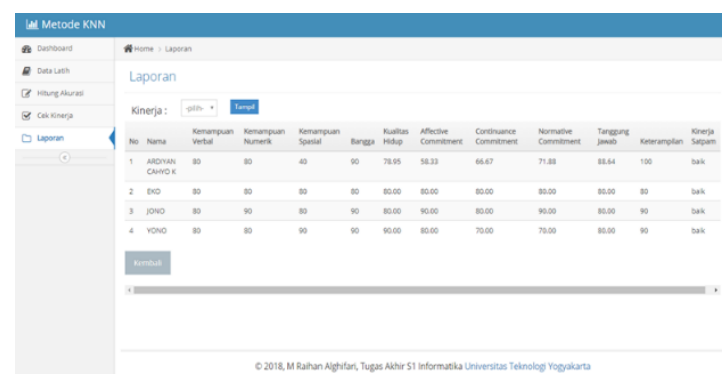

Gambar 17. Tampilan Laporan

\section{KESIMPULAN}

Dari hasil analisa dan perancangan sistem klasifikasi kinerja satpam dengan menggunakan metode k-nn, maka dapat diambil kesimpulan diantaranya adalah sebagai berikut:

a. Metode KNN bisa digunakan untuk klasifikasi kinerja satpam dengan menggunakan 10 kolom inputan nilai ke dalam sistem sebagai data uji yang akan dihitung dengan seluruh data latih untuk memperoleh hasil kinerjanya.

b. Perhitungan akurasi menggunakan 6 data uji dan 130 data latih yang menghasilkan nilai kebenaran sebesar $66,67 \%$.

\section{REFRENSI}

[1] Eko, W., (2015), Manajemen Pengembangan Sumber Daya Manusia, Yogyakarta: Pustaka Pelajar.

[2] Kuhkan, M., (2016), A Method to Improve the Accuracy of K-Nearest Neighbor, Int. J. Comput. Eng. Inf. Technol, 8(6), 90-95.

[3] Raharjo, B., Heryanto, I. dan Rosdiana K, E., (2014), Modul Pemrograman Web (HTML, PHP \& MySQL), Revisi Ked Bandung: Modula.

[4] Mundzir, M.F., (2014), PHP Tutorial Book for Beginner, Yogyakarta: NOTEBOOK.

[5] Kadir, A., (2014), Pengenalan Sistem Informasi, Revisi Yogyakarta: Andi Ofset.

[6] Rosa, A.S. dan Shalahuddin, M., (2014), Rekayasa Perangkat Lunak Terstruktur dan Berorientasi Objek, 
Bandung: Informatika Bandung.

[7] Wibowo, A.P. dan Hartati, S., (2016), Sistem Klasifikasi Kinerja Satpam Menggunakan Metode Naïve Bayes Classifier Sistem Klasifikasi Kinerja Satpam Menggunakan Metode Naïve Bayes Classifier, Jurnal Inovtek Polbeng, 1(2), 192-201. 